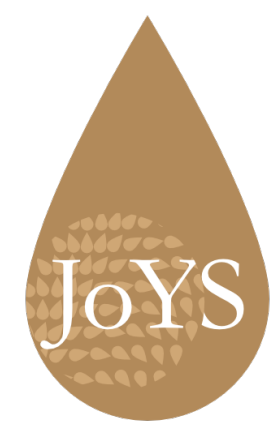

\title{
EDITORIAL: Jumping over the Threshold
}

\author{
Elizabeth De Michelis and Jacqueline Hargreaves \\ Senior Editor and Production Editor
}

Dear Readers,

It is a great pleasure to write this short note of introduction to the 2019 volume of the Journal of Yoga Studies (JoYS). In this volume we publish two items: a long article providing a stimulating, informative, and substantial contribution to academic research on Yoga, and the first of what we hope will be a long series of insightful book reviews. Suggestions about works to review which fall within the scope of our journal are always welcome.

The field of Yoga studies continues to flourish with specialist Masters-level degree programmes now available in Korea, Italy, UK, USA, and Germany, and in recent years universities across Europe have launched intensive 'Yoga Studies Summer School' programmes to complement such degrees. We feel very pleased to showcase academic excellence in this burgeoning research discipline. The growth of notable membership to our Advisory and Editorial Boards is also reassuring.

As in the case of volume one, the two pieces published herein are indicative of the standards of contributions that we seek. We received many submissions throughout the year but, unfortunately, they were not suitable for publication for various reasons. In this context it may be worth pointing out that, as stated in our presentation page, "JoYs does not accept submissions of natural sciences, medical or experimental psychology articles, but would welcome review or analytical articles written by specialists in these fields with the specific aim of reporting relevant findings to non-specialist academic 
readers." This is not to say that the types of submissions listed at the beginning of the quotation would not be interesting and worthwhile - it's simply that we do not have the suitable expertise and contacts to evaluate, review, and process them as required. Such limitations apart, we are always grateful to receive new article proposals, as they tell us something about what is going on in our field and sometimes give us a chance to interact in fruitful ways with colleagues and students near and far.

We would also like to say a few words about this volume's cover and how it links with Birch and Singleton's article on the Hathābhyāsapaddhati. The photograph reproduced is in fact a still from a film, which aims to re-enact the extraordinary postural practice of this eighteenth-century text, and features its Sanskrit recitation along with an English translation (see http://hathabhyasapaddhati.org). This unique film was conceived and directed by one of us (Jacqueline Hargreaves) in collaboration with the Hatha Yoga Project, SOAS (http://hyp.soas.ac.uk). Such a pioneering project could be described as an experiment in 'embodied philology' - an innovative way in which philological research can make an impact on the wider community by way of interdisciplinary collaborations that aim to bring to life, via film and other mediums, the unique content of premodern Sanskrit manuscripts. The re-enactment required the invaluable support of passionate and adept practitioners in both India and the UK. The äsana masterfully demonstrated on the cover is called 'jumping over the threshold' (dehalyullanghan$\bar{a}$ sana). It is indicative of the skill and physical strength required to perform some of the dynamic premodern āsanas of the Hațhäbhyāsapaddhati. Segments of this film will be a central feature of the forthcoming exhibition entitled Embodied Liberation: The Textual, Ethnographical and Historical Research of the Hatha Yoga Project, which will take place at the Brunei Gallery in London from 16th January to 21st March 2020.

As 2019 draws to a close and we get ready to jump over this 'calendar threshold,' we look forward to sharing more exciting Yoga research with our readers in the coming year. In the meantime, we wish you every academic success for 2020 !

Elizabeth De Michelis and Jacqueline Hargreaves on behalf of the JoYS Editorial Team:

Jason Birch

Matthew Clark

Suzanne Newcombe 